\title{
Using Remote Sensing to Monitor Global Change
}

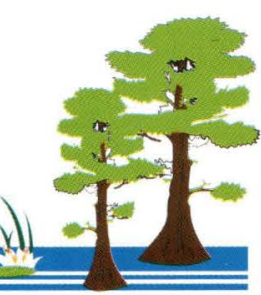

$\mathbf{T}$

properly respond to natural and human-induced stresses to wetlands, resource managers must consider their functions and values. Remote sensing is an important tool for monitoring wetland responses to changes in the hydrologic regime and water quality caused by global climate change and sea-level rise.

Extensive marshes, swamps, and mangrove forests fringe most of the U.S. coastline. Besides being an important source of nutrients, coastal wetlands are nurseries for fish and shrimp and habitat for many birds and fur-bearing animals. They are also vital to coastal recreation, maintain water quality, and serve as a buffer against shore erosion.

In the United States, widespread wetland loss has resulted from the filling of marshlands, construction of canals and waterways, and diversion of river sediments offshore. Soil conservation practices and floodcontrol structures such as dams and levees are preventing sediments from reaching wetlands. Further compounding these human-induced stresses, the eustatic sea-level rise has serious implications for coastal wetlands. Predominantly, the sea level is rising globally from $1 \mathrm{~mm}$ to $2 \mathrm{~mm}$ yearly; however, increasing rates are predicted to cause about a $50-\mathrm{cm}$ rise in sea level by the year 2100 . These problems are especially pertinent to coastal wetlands where the rate of elevation rise may only be about 10 $\mathrm{cm}$ for each kilometer traversed inland. If the "greenhouse effect" is confirmed as part of the global climate change scenario, even these levels will be outpaced.

Coastal hydrology is dominated by surface topography, surface drainage, soil character, and local tidal dynamics. With an increasing rate of sealevel rise, tidal dynamics will dominate the hydrology changes within low-lying coastal wetlands. Impacts to these wetlands will include changes in soil salinity levels, flooding duration and frequency, and water quality. Forecasts of how these changes will affect the present and future wetland species zonation are needed. To make these forecasts, it is necessary to first identify the relationship between wetland type and hydrology. Remote sensing studies conducted by USGS scientists focused on integrating groundbased and satellite measurements to develop tools for measuring and monitoring factors critical to determining these linkages (Fig. 1). They also developed techniques for generating coastal topography to simulate future wetland changes based on uncovered linkages and sea-level rise scenarios.

\section{Wetland Types}

A progressive classification of a marsh and forest system combining

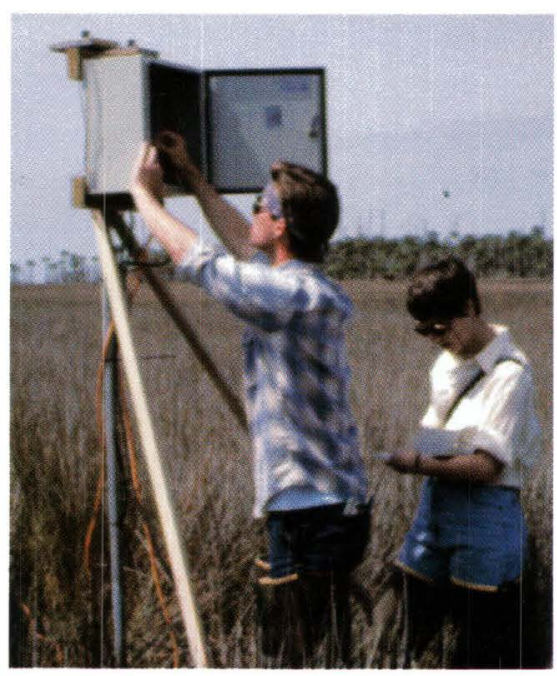

Fig. 1. Researchers monitoring salinity and water depth at St. Marks National Wildlife Refuge for comparison with satellite data. data from Landsat Thematic Mapper (TM), color infrared photography, and ERS-1 satellite radar was developed that improved classification accuracy and resulted in a detailed identification of differences within a nearly monotypic black needlerush marsh in Florida. These types of improvements in classifying coastal land covers are necessary before an accurate portrayal of the link between vegetation characteristics and hydrology can be made.

\section{Vegetation Biomass}

Vegetation indexes related to biomass measures were generated from passive microwave data and Landsat TM data. The optical TM vegetation index based on red and near-infrared wavelengths is primarily linked to changes in green biomass. The microwave vegetation index based on measuring energy emitted at $6-\mathrm{cm}$ and $21-\mathrm{cm}$ microwave wavelengths is primarily responsive to the vegetation water content. The images are noticeably similar (Fig. 2). If the microwave instrument proves to be an adequate estimator of biomass in these wetlands, a monitoring program could be developed around this all-weather, day-and-night sensor.

\section{Monitoring Flooding}

Satellite radar was used to map tidal flooding, a critical control of coastal vegetation distribution. Radar images taken during a time of nearcontinuous recordings of ground based hydrology measurements directly linked marsh flooding to lowered radar returns (Fig. 3). Combined with 

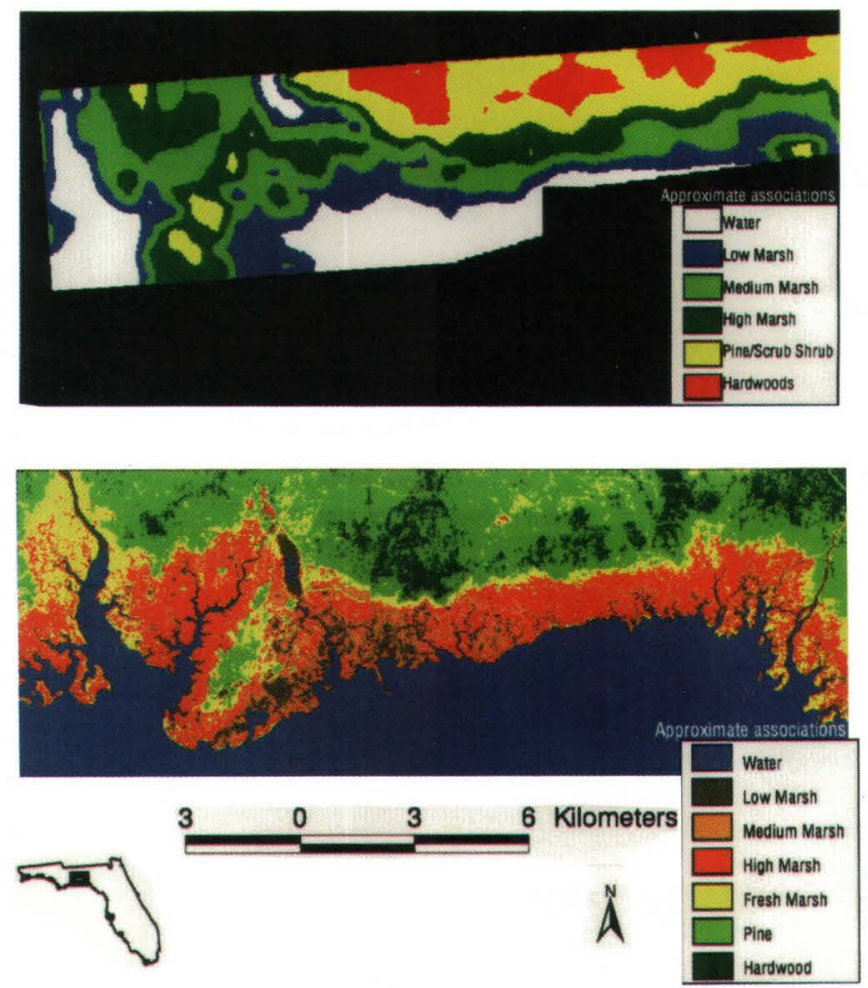

Fig. 2. Vegetation indexes of biomass within marsh and forested wetlands generated from (top) passive microwave data and (bottom) Landsat Thematic Mapper data.

point measurements of inundation and surface topography, the all-weather, day-and-night instrument could allow dynamic monitoring of flood status and the generation of flood-depth surfaces.

\section{Surface Micro Topography}

A topographic surface model of a low-lying coastal marsh was created by using three flood extent vectors digitized from satellite radar images and two elevation contours from USGS topographic quadrangles. Excluding abrupt boundaries and topographic highs and lows outside the range of available contours, standard deviation of differences

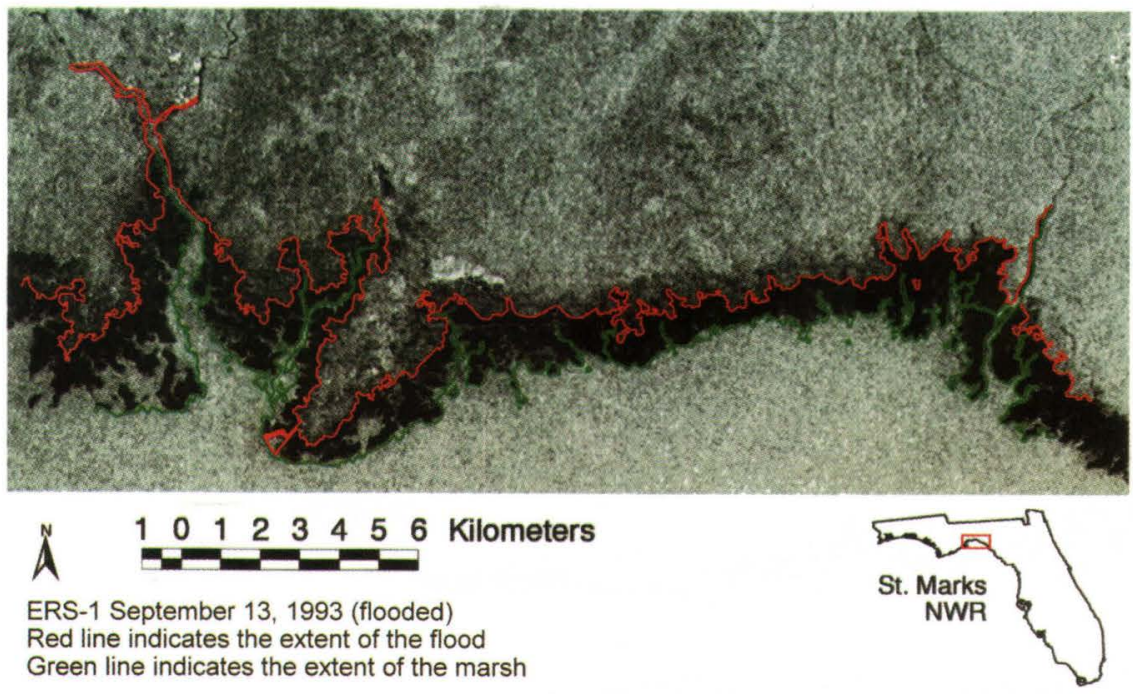

Fig. 3. Satellite radar images of coastal flooding of a Florida black needlerush marsh. 